\title{
REVISÃO: TÉCNICAS USADAS NO PROCESSO DE PURIFICAÇÃO DE BIOMOLÉCULAS
}

\author{
ABRAHAM DAMIAN GIRALDO ZUÑIGA * \\ JOSÉ ANTONIO MARQUES PEREIRA ** \\ JANE SELIA REIS COIMBRA ** \\ LUIS ANTONIO MINIM ** \\ EDWIN ELARD GARCIA ROJAS *
}

\begin{abstract}
A presente revisão da literatura teve por objetivo mostrar as diferentes técnicas que podem ser empregadas no processo de purificação de biomoléculas. Além da seleção e combinação de técnicas de separação para o desenvolvimento da estratégia de purificação foram abordadas a precipitação, a centrifugação, a tecnologia de membranas (osmose reversa, ultrafiltração, diálise e microfiltração), a extração líquido-líquido usando sistemas aquosos bifásicos, as técnicas cromatográficas (troca iônica, interação hidrofóbica, fase reversa, exclusão molecular, leito expandido), as separações biosseletivas (cromatografia por afinidade, precipitação por afinidade, partição de proteínas por afinidade em sistemas aquosos bifásicos) e novas técnicas de separação (leito móvel simulado, micelas reversas e cromatografia em contracorrente). Verificou-se que as técnicas cromatográficas estão presentes em todos os processos de purificação de biomoléculas, embora ainda existam restrições técnicas e econômicas na aplicação de alguns tipos de cromatografia em escala preparativa.
\end{abstract}

PALAVRAS-CHAVES: BIOMOLÉCULAS; TÉCNICAS CROMATOGRÁFICAS; PROCESSOS DE PURIFICAÇÃO.

\section{INTRODUÇÃO}

O interesse crescente pelos processos de purificação de biomoléculas deve-se principalmente ao desenvolvimento da biotecnologia e à demanda das indústrias farmacêutica e química por produtos com alto grau de pureza. A indústria de alimentos também apresentou aumento no uso de biomoléculas, como enzimas e proteínas, principalmente em cervejarias e em processos de fermentação.

* Alunos de pós-graduação em Ciência e Tecnologia de Alimentos, Universidade Federal de Viçosa (UFV), Viçosa, MG (e-mail: abraham@vicosa.ufv.br).

** Professores do Departamento de Tecnologia de Alimentos (DTA), UFV, Viçosa, MG. 
O objetivo deste trabalho de revisão é mostrar os diferentes tipos de técnicas que podem ser usadas nas etapas do processo de purificação e as técnicas promissoras que podem ser aplicadas na purificação de biomoléculas.

\section{PROCESSO DE PURIFICAÇÃO}

O esquema básico para a separação de biomoléculas foi sugerido por pesquisadores, liderados pelo químico Arthur B. Little, em 1917 (16). Esse comitê considerou que as separações químicas poderiam ser classificadas como "operações unitárias", que incluem destilação, adsorção, filtração, etc. Os pesquisadores argumentaram que a inclusão da destilação foi baseada em idéias comuns, já que era usada para purificar óleo cru ou para fazer conhaque. Tal inclusão gerou grande polêmica, pois outros cientistas consideravam impossível o uso da destilação para muitos materiais biológicos. Foi questionado que somente alguns compostos de baixo peso molecular poderiam ser destilados, tais como os aromas. Entretanto, a destilação não serviria para a separação de antibióticos, hormônios e proteínas. Em 1986, BELTER sugeriu que cada separação fosse considerada como quatro passos seqüenciais, ou seja, clarificação ou remoção de compostos insolúveis, isolamento do produto ou concentração, purificação intermediária e polimento. Essa foi a melhor estratégia para a purificação de biomoléculas, sendo utilizada em processos biotecnológicos como base para o desenvolvimento de processos de purificação de proteínas, enzimas, células e hormônios. Tal estratégia também mostrou-se eficiente no desenvolvimento de novas rotas ou esquemas de purificação em nível de pesquisa de laboratório e industrial (16).

\subsection{SELEÇÃO E COMBINAÇÃO DE TÉCNICAS DE SEPARAÇÃO PARA DESENVOLVER A ESTRATÉGIA DE PURIFICAÇÃO}

No esquema proposto por BELTER (1986), a purificação de biomoléculas exige o emprego de muitas técnicas devendo-se buscar a mais apropriada para cada estágio de separação. Assim, são empregadas técnicas diferentes na remoção de compostos insolúveis ou clarificação, no isolamento do produto ou captura, na purificação intermediária e no polimento (Tabela 1). Por exemplo, para o isolamento e purificação de enzimas são usadas técnicas como homogeneização, centrifugação, filtração, evaporação e cromatografia (10). As técnicas cromatográficas estão presentes em todos os processos de purificação. Com a utilização 
dessas em seqüência é possível purificar uma única enzima das muitas presentes num extrato celular. Por essa razão, NIVEN (1995) afirmou que a cromatografia representava o estado da arte na purificação de proteínas.

A disponibilidade de diferentes técnicas cromatográficas com diferentes propriedades fornece combinação poderosa para a purificação de qualquer biomolécula (64). A quantidade e tipo de técnicas usadas dependerão da natureza e das características das amostras, assim como do grau de pureza desejado no produto final (61).

\section{TABELA 1 - TÉCNICAS DE SEPARAÇÃO QUE PODEM SER USADAS NAS DIFERENTES ETAPAS DO PROCESSO DE PURIFICAÇÃO}

\begin{tabular}{|c|c|c|c|c|}
\hline \multirow[b]{2}{*}{ TØcnica de separa $\stackrel{a}{0}$} & \multicolumn{4}{|c|}{ Est/Egios ou etapas } \\
\hline & Clarifica $\stackrel{a}{\circ} 0$ & $\begin{array}{l}\text { Captura ou } \\
\text { primeira } \\
\text { purifica o o }\end{array}$ & $\begin{array}{c}\text { Purifica } \stackrel{a}{0} \\
\text { intermediÆজia }\end{array}$ & Polimento \\
\hline Precipita ${ }^{a} 0$ & $\star$ & $\star$ & $\star$ & \\
\hline Centrifuga ${ }^{a} 0$ & $\star$ & & & \\
\hline Homogeneiza a & $\star$ & & & \\
\hline Filtra a 0 & $\star$ & & & \\
\hline Cristaliza ${ }^{a} 0$ & & & $\star$ & \\
\hline $\begin{array}{l}\text { Sistemas aquosos } \\
\text { bif } / \text { sicos }\end{array}$ & $\star$ & $\star$ & $\star$ & \\
\hline $\begin{array}{l}\text { Cromatografia de troca } \\
\text { i nica }\end{array}$ & & $\star \star \star$ & $\star \star \star$ & $\star \star \star$ \\
\hline $\begin{array}{l}\text { Cromatografia com ligante } \\
\text { espec fico (afinidade) }\end{array}$ & & $\star \star \star$ & $\star \star \star$ & $\star \star$ \\
\hline $\begin{array}{l}\text { Cromatografia por } \\
\text { intera o hidrof bica }\end{array}$ & & $\star \star$ & $\star \star \star$ & $\star$ \\
\hline $\begin{array}{l}\text { Cromatografia por } \\
\text { exclus } \stackrel{a}{\circ} \text { molecular }\end{array}$ & & & $\star$ & $\star \star \star$ \\
\hline Diafiltra $\stackrel{a}{0}$ & & & & $\star$ \\
\hline UItrafiltra ${ }^{a} 0$ & & & & $\star$ \\
\hline $\begin{array}{l}\text { Cromatografia em fase } \\
\text { reversa }\end{array}$ & & & $\star \star$ & $\star \star \star$ \\
\hline
\end{tabular}

Fonte: MATEJTSCHUK et al. (1998), BROCKLEBANK (1990) e PHARMACIA BIOTECH (1999).

Na escolha de técnicas cromatográficas, comumente, são empregados os critérios de recuperação, resolução, velocidade e capacidade (Tabela 2). 


\section{TABELA 2 - PARÂMETROS CARACTERÍSTICOS DAS TÉCNICAS USADAS NO PROCESSO DE PURIFICAÇÃO}

\begin{tabular}{|c|c|c|c|c|}
\hline TØenica & Capacidade & Velocidade & Resolu ${ }^{a} 0$ & Rendimento \\
\hline Cromatografia por troca i nica & Alta -MØdia & Alta & Alta MØdia & MØdio \\
\hline $\begin{array}{l}\text { Cromatografia por intera } \stackrel{a}{0} 0 \\
\text { hidrof bica }\end{array}$ & MØdia & Alta & MØdia & MØdio \\
\hline Focaliza $\stackrel{a}{\circ}$ o IsoelØrica & Baixa & - & Alta & MØdio \\
\hline Cromatografia por afinidade & MØdia-Baixa & Alta & Muito Alta & Baixo \\
\hline $\begin{array}{l}\text { Cromatografia por exclus }{ }^{\mathrm{a}} 0 \\
\text { molecular }\end{array}$ & Muito Baixa & MØdia & Alta Baixa & MØdio \\
\hline
\end{tabular}

Fonte: Adaptado de HARRIS e ANGAL (1995) e PHARMACIA BIOTECH (1999).

\section{TÉCNICAS USADAS NO PROCESSO DE PURIFICAÇÃO DE BIOMOLÉCULAS}

A purificação de determinada biomolécula envolve uma série de etapas convenientemente ordenadas, visando a obtenção do máximo de rendimento e pureza, além de custos compatíveis com os de mercado.

\subsection{PRECIPITAÇÃO}

A precipitação e conseqüente recuperação de proteínas solúveis, mediante a adição de reagentes ou de soluções, constitui técnica simples e rápida para a concentração de proteínas (79). É muito empregada pelas indústrias como operação inicial no processo de purificação, reduzindo em grande parte o volume do meio reacional para estágios posteriores (23). Essa técnica geralmente não é utilizada na recuperação de células presentes em meios muito diluídos (11). Algumas aplicações dessa técnica são mostradas na Tabela 3.

\subsection{CENTRIFUGAÇÃO}

As centrífugas são muito usadas em processos de escala piloto ou comercial para separar sólidos, desde caseínas, glutinas, leveduras, bactérias e células até meios fermentados contendo enzimas funcionais, anticorpos e proteínas terapêuticas. Diversas centrífugas comerciais estão disponíveis no mercado, que no entanto é dominado por dois fabricantes pincipais, a Westfalia Separator AG (Oelde, Germany) e a Alfa Laval 
Separation (Tumba, Sweden) (56). Dentre outras aplicações, essa operação é utilizada na recuperação de isolados protéicos e de proteínas dos processos de lavagem, na separação de leveduras e na clarificação de óleo animal (82). Além de ocupar pequena área na planta, as vantagens da centrifugação incluem: agilidade na separação, boa capacidade para retirar água, baixo custo de operação e capacidade para separar a maior parte de materiais celulares.

\section{TABELA 3 - APLICAÇÕES DA PRECIPITAÇÃO COM DIFERENTES TIPOS DE AGENTES PRECIPITANTES}

\begin{tabular}{lcc}
\hline Prote na & $\begin{array}{c}\text { Agente } \\
\text { precipitante }\end{array}$ & ReferCfrcia \\
\hline$\beta$-amilase & Alginato & $(79)$ \\
Lactoperoxidase & $\mathrm{CMC}$ & $(48)$ \\
$\alpha$-amilase & Alginato & $(72)$ \\
Xilanase & Alginato & $(28)$ \\
Endopoligalacturonase & Alginato & $(27)$ \\
Prote nas do soro de leite & Cloreto de ferro & $(47)$ \\
exceto a $\beta$-Ig & $\left(\mathrm{NH}_{4}\right)_{2} \mathrm{SO}_{4}$ & $(6)$ \\
Glicerol fosfato desidrogenase & cido poliacr lico $_{\text {Lisozima }}$ & $(76)$ \\
Icool oxidase & Polietilenoglicol & $(38)$ \\
\hline
\end{tabular}

\subsection{TECNOLOGIA DE MEMBRANAS}

Os sistemas de separação por membranas foram usados durante muito tempo nos processos da indústria química, sendo depois empregados pela indústria de alimentos. As aplicações típicas na indústria de alimentos incluem a purificação da água, a concentração e a clarificação de sucos de frutas, de produtos lácteos, de bebidas alcoólicas e no tratamento de águas (75). Nos sistemas de separação por membrana, o fluido contendo dois ou mais componentes é colocado em contato com uma membrana que permite a passagem seletiva de alguns componentes mais rápida do que de outros. A natureza física e química das membranas (como, por exemplo, o tamanho do poro e a distribuição do tamanho do poro) afetam diretamente a separação (Tabela 4).

Os processos da tecnologia de membrana, divididos em osmose reversa (OR), ultrafiltração (UF), microfiltração (MF) e diálise (D) oferecem vantagens na recuperação de bioprodutos. Tais vantagens, segundo FANE e RADOVICH (19), envolvem a facilidade no escalonamento dos equipamentos, elevada estabilidade, o processo ocorre em temperaturas moderadas, o estresse químico e físico pode ser minimizado, além de 
permitir que a concentração e a purificação possam ser obtidas em uma única etapa.

As membranas empregadas pela osmose reversa (OR) são caracterizadas pelo tamanho de corte de massa molecular de, aproximadamente, $100 \mathrm{Da}$, cujo processo envolve pressões 5 a 10 vezes maiores que a ultrafiltração (70). Na técnica de ultrafiltração (UF) a faixa de pressão varia de 70 a $700 \mathrm{kPa}$ e o tamanho dos poros de 0,001 a 0,02 m, com ponto de corte de 1000 a $80000 \mathrm{Da}$ (75). A ultrafiltração está emergindo gradativamente como processo de biosseparação importante para a purificação e polimento de bioprodutos como drogas terapêuticas, enzimas, hormônios, anticorpos, etc. (71). A microfiltração (MF) constitui extensão da UF, porém as membranas apresentam tamanho de poro maior. As macromoléculas passam através da membrana, ficando retidos os colóides e as células (19). O tamanho do poro varia de $0,2-2,0 \mu \mathrm{m}$, podendo separar de forma seletiva as partículas com massa molecular acima de $200 \mathrm{kDa}(70)$.

\section{TABELA 4 - APLICAÇÃO DAS DIFERENTES MEMBRANAS NA SEPARAÇÃO DE VÁRIOS COMPOSTOS}

\begin{tabular}{|c|c|c|c|c|c|c|}
\hline \multirow[t]{2}{*}{ Compostos } & \multirow{2}{*}{$\begin{array}{l}\text { Massa Molar } \\
\text { (Da) }\end{array}$} & \multirow{2}{*}{$\begin{array}{c}\text { Tamanho } \\
(\mathrm{nm})\end{array}$} & \multicolumn{4}{|c|}{ Compostos retidos } \\
\hline & & & OR & UF & MF & $\mathrm{D}$ \\
\hline Leveduras e Fungos & & $10^{3}-10^{4}$ & & & $X$ & \\
\hline Bactørias & & $300-10^{4}$ & & - & $\mathrm{x}$ & $\mathrm{X}$ \\
\hline Col ides & & $100-10^{3}$ & & $\mathrm{X}$ & $\mathrm{X}$ & $\mathrm{X}$ \\
\hline V rus & & $30-300$ & & $\mathrm{X}$ & $\mathrm{x}$ & $\mathrm{X}$ \\
\hline Prote nas & $10^{4}-10^{6}$ & $2-10$ & & $x$ & & $x$ \\
\hline Polissacar deos & $10^{4}-10^{6}$ & $2-10$ & & $\mathrm{x}$ & & $\mathrm{x}$ \\
\hline Enzimas & $10^{4}-10^{6}$ & $2-5$ & - & $x$ & & $x$ \\
\hline Antibi ticos & $300-10^{3}$ & $0,6-1,2$ & - & & & - \\
\hline A œares Simples & $200-400$ & $0,8-1,0$ & $\mathrm{x}$ & & & \\
\hline cidos Org nicos & $100-500$ & $0,4-0,8$ & $\mathrm{X}$ & & & \\
\hline "ons Inorg nicos & $10-100$ & $0,2-0,4$ & $\mathrm{X}$ & & & \\
\hline
\end{tabular}

Fonte: FANE e RADOVICH (1990).

OR $=$ Osmose Reversa.

UF = Ultrafiltração.

$\mathrm{MF}=$ Microfiltração.

$\mathrm{D}=$ Diálise.

\subsection{EXTRAÇÃO LÍQUIDO-LÍQUIDO USANDO SISTEMAS AQUOSOS BIFÁSICOS}

A extração líquido-líquido convencional usando solução aquosa e solventes orgânicos não é adequada para separar biomoléculas (como proteínas), devido à sua baixa estabilidade em solventes orgânicos (78). A alternativa 
adequada para os processos tradicionais de biosseparação é a partição em sistemas aquosos bifásicos ( $\mathrm{SAB}$ ), que vem sendo usada com sucesso no isolamento de proteínas e de outros materiais de origem biológica $(1,46)$. Os $S A B$ resultam da incompatibilidade de dois polímeros em soluções, por exemplo, polietilenoglicol (PEG) e dextrana ou entre um polímero e um sal (como PEG e fosfato de potássio). A incompatibilidade ocorre em função da concentração desses compostos (2, 14). A alta concentração de água (de $65 \%$ a $90 \%$ ) em tais sistemas favorece a estabilidade das proteínas durante a separação, quando comparados com sistemas tradicionais compostos com solventes orgânicos (50). Os sistemas PEG-sal têm sido usados para extração de enzimas em larga escala (34) por apresentarem baixo custo e elevada seletividade das proteínas $\alpha$-lactoalbumina e $\beta$-lactoglobulina $(14,22)$. Outra vantagem dos $\mathrm{SAB}$ é a reciclagem dos seus componentes (69). Extensa revisão de literatura sobre o assunto pode ser encontrada em COIMBRA et al. (13).

\subsection{TÉCNICAS CROMATOGRÁFICAS}

As separações cromatográficas consistem na partição do soluto entre uma fase móvel e outra estacionária. Comumente, a fase estacionária é sólida, sendo formada por matriz de partículas empacotadas em coluna de forma tubular. A fase móvel que contém a mistura de componentes a serem separados passa através da coluna. A alimentação é introduzida na coluna como um pulso e os componentes individuais são separados devido à sua distribuição diferencial entre as fases (17). Separações com altas resoluções podem ser obtidas pela mudança gradual na fase móvel, mediante o emprego de eluição em gradiente (59).

\subsubsection{Cromatografia de Troca lônica}

Na cromatografia de troca iônica, a separação ocorre de acordo com a carga das biomoléculas. Foi constatado que esse é o método de purificação de proteínas mais comumente empregado. Além disso, é utilizado com muita efetividade pelas indústrias de bioquímica fina e farmacêutica para o escalonamento dos processos de isolamento de proteínas (21).

Muitos tipos de adsorventes e colunas empregadas na cromatografia de troca iônica encontram-se disponíveis no mercado. Como exemplo tem-se o sistema BioPilot da Pharmacia ${ }^{\circledR}$, capaz de operar coluna preparativa (HR 50/10) com vazão de $30 \mathrm{~mL} / \mathrm{min}$ e alimentação da amostra de até $4 \mathrm{~g}$ 
por ciclo (61). Os processos em nível industrial que utilizam esse tipo de cromatografia para purificar as proteínas do soro de leite são o BiPRO ${ }^{\circledR} \mathrm{e}$ os processos Vistece Spherosil $(18,58)$. Algumas outras aplicações da cromatografia de troca iônica estão compiladas na Tabela 5.

\section{TABELA 5 - APLICAÇÕES DA CROMATOGRAFIA DE TROCA IÔNICA NA SEPARAÇÃO DE BIOMOLÉCULAS}

\begin{tabular}{llc}
\hline Biomoløula & Tipo de Resina & ReferCfrcia \\
\hline$\beta$-galactosidase & Accel Plus QMAfi & $(62)$ \\
$\alpha$-la, $\beta$-lg e BSA & Q-sepharose fi, & $(21)$ \\
$\alpha$-la e imunoglobulina & $\begin{array}{l}\text { S-Sepharose fi } \\
\text { S-Sepharose, Fractogel }\end{array}$ & $(29)$ \\
$\beta$-lg & EMD, S-Hyper D-F \\
BSA & Celite trans-retinal \\
$\beta$-lactoglobulina & Accel Plus QMAfi \\
$\beta$-caseina & Celite trans-retinal & $(31)$ \\
$\alpha$-la e $\beta$-lg & Mono Sfi & $(3)$ \\
\end{tabular}

$\alpha-\mathrm{la}=$ alfalactoalbumina; $\beta-\mathrm{lg}=$ betalactoglobulina e BSA = albumina do soro bovino.

\subsubsection{Cromatografia por Interação Hidrofóbica $(\mathrm{CIH})$}

A cromatografia por interação hidrofóbica $(\mathrm{ClH})$ foi desenvolvida nos anos 1970 (67) para a separação de proteínas, mediante o uso de colunas empacotadas com resinas de agarose modificada. Em 1980 foram desenvolvidas novas micropartículas para serem empregadas como fase estacionária, tornando possível a utilização da $\mathrm{CIH}$ mediante a cromatografia líquida de alta eficiência (HPLC).

A ClH, usada para separar proteínas com hidrofobicidade diferentes, é ideal para ser empregada na etapa de captura de biomoléculas ou no estágio de purificação intermediária (64). Fosfato de amônio ou sais de sulfato são efetivos para promover interações hidrofóbicas. Essa técnica em combinação com sistemas aquosos bifásicos também tem mostrado bons resultados na extração de proteínas a partir de um meio de células não-clarificado (7). Algumas aplicações da $\mathrm{CIH}$ podem ser observadas na Tabela 6. 
TABELA 6 - APLICAÇÕES DA CIH NA SEPARAÇÃO DE BIOMOLÉCULAS

\begin{tabular}{lc}
\hline Composto & ReferC̄cia \\
\hline$\alpha$-amilase & $(49)$ \\
EstrogCæio & $(35)$ \\
$\beta$-amilase & $(57)$ \\
Albumina e $\gamma$-globulina do soro humano & $(24)$ \\
Lipoxidase & $(44)$ \\
Glucose isomerase & $(45)$ \\
Glucosidases & $(43)$ \\
\hline
\end{tabular}

\subsubsection{Cromatografia de Fase Reversa (CFR)}

Mediante a utilização de cromatografia de fase reversa podem ser obtidas separações com elevada rapidez, ou seja, 20 segundos em alguns casos (53). O tempo rápido de separação auxilia o monitoramento de bioprocessos que requerem análises periódicas dos compostos mediante HPLC. A CFR é considerada técnica de alta resolução para a análise de proteínas, mas o seu uso em escala preparativa é limitado devido à não-preservação da integridade estrutural das proteínas (67). Desta forma, a CFR é muito usada nos laboratórios de pesquisa, em laboratórios de análise de alimentos e no controle de qualidade. No entanto, pode ser empregada em processos de purificação de compostos biofarmacêuticos em grande escala.

As fases estacionárias usadas na CFR são estáveis em ampla faixa de pH (1 a 13) e adequadas para a separação de peptídios e proteínas. As fases móveis típicas empregadas são misturas orgânicas-aquosas, contendo metanol, isopropanol e acetonitrila dentre outros como modificadores orgânicos (80).

\subsubsection{Cromatografia por Exclusão Molecular (CEM)}

$\mathrm{Na}$ cromatografia por exclusão molecular (CEM), a separação ocorre de acordo com o tamanho efetivo das moléculas. A coluna é recheada com material inerte cujo tamanho dos poros é controlado. As moléculas pequenas podem penetrar na maioria dos poros apresentando maior tempo 
de retenção, enquanto as maiores são excluídas de todos os poros. Assim, moléculas grandes movem-se rapidamente através da coluna e as pequenas são eluídas lentamente pela fase móvel $(15,36)$.

A CEM é empregada há mais de quatro décadas como técnica de separação, dessalinização e para estimar a massa molecular de peptídios e proteínas (36). O desenvolvimento de diferentes tipos de géis e a existência de colunas comerciais empacotadas contribuíram para melhorar a resolução das separações e também para diminuir o tempo de análise. Tal fato provocou rápido aumento no uso da CEM como técnica de separação e purificação de macromoléculas. A CEM também é usada para separar monômeros, dímeros, trímeros, imunoglobulinas, anticorpos, produtos de reações de mistura complexa e diversas outras aplicações (68).

\subsubsection{Cromatografia em Leito Expandido}

$\mathrm{Na}$ adsorção em leito expandido as partículas não são empacotadas firmemente na coluna (9). Esse tipo de cromatografia exige apenas uma etapa para purificar a proteína desejada a partir de meio "in natura", sem precisar de clarificação inicial do meio, concentração ou purificação inicial (64).

A fase estacionária do leito expandido é equilibrada, na forma expandida, com o tampão de equilíbrio (Figura 1). A amostra contendo as células é aplicada, no sentido de baixo para cima (etapa 2), no leito estabilizado. Desta forma, a proteína de interesse e alguns contaminantes adsorvem na resina, enquanto as células saem pela parte superior da coluna. $O$ tempo para que a proteína alvo seja adsorvida depende do fluxo de aplicação da amostra, bem como da quantidade de resina utilizada na expansão (9). Após a aplicação da amostra a resina é lavada de baixo para cima (etapa 3), com o tampão de lavagem, para remoção dos restos celulares e das proteínas não-adsorvidas pela resina. A etapa de eluição da proteína de interesse (etapa 4) é efetuada de cima para baixo, ou seja, após sedimentação do leito. Em seguida, a coluna é limpa e regenerada para novo uso (etapa 5). O propósito dessa tecnologia é combinar as etapas de clarificação e adsorção em uma só, a fim de aumentar o rendimento e diminuir o tempo de processo, os custos, etc.

A cromatografia em leito expandido pode substituir as etapas de clarificação e concentração do produto (64) que representam grande problema para as indústrias farmacêuticas. 
FIGURA 1 - ETAPAS DE UM SISTEMA DE PURIFICAÇÃO EM LEITO EYDANInInก

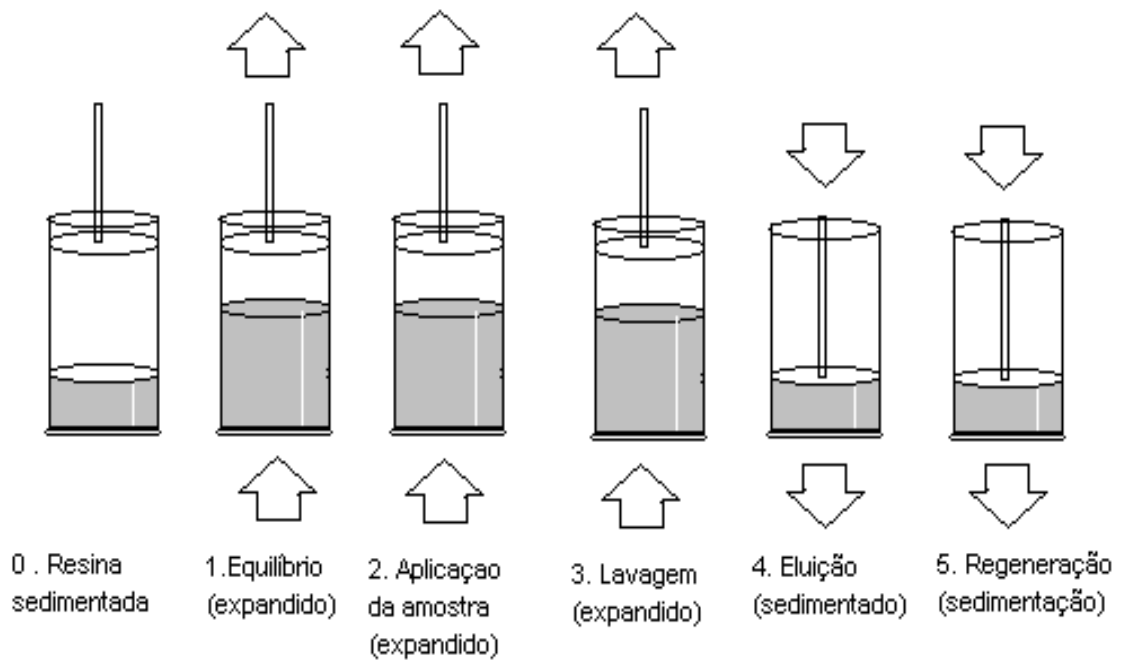

\subsection{SEPARAÇÕES BIOSSELETIVAS}

\subsubsection{Cromatografia por Afinidade Química}

A forma mais comum de efetuar separações biosseletivas é a cromatografia por afinidade. Pesquisas de dados na literatura revelam que dentre os métodos cromatográficos existentes, a cromatografia por afinidade é a segunda técnica mais comumente usada na purificação (12). Nessa técnica, os compostos (com afinidade pelo ligante) são imobilizados em matriz cromatográfica mediante ligação seletiva reversível do ligante com a molécula de interesse (59). É ideal para a captura ou purificação intermediária de biomoléculas, podendo ser usada sempre que houver ligante adequado para a proteína de interesse (64).

A especificidade oferecida pela cromatografia por bioafinidade pode ser aproveitada para obtenção de biosseparações com elevado grau de seletividade (31). Para aumentar a eficiência dessa técnica, o material de suporte não deve ligar as proteínas não-desejadas. Os sistemas de bioafinidade são os mais poderosos métodos de separação disponíveis, devido ao alto grau de resolução, capacidade e seletividade que se pode 
obter. Por essa razão são freqüentemente usados em escala preparativa para a purificação comercial de produtos farmacêuticos, de pesquisa e para a remoção de contaminantes específicos como as proteases (64).

\subsubsection{Filtração por Afinidade}

O uso de interações por bioafinidade não se restringe apenas às colunas cromatográficas. Vários tipos de suporte podem ser usados para aumentar a seletividade de técnicas com baixa resolução na separação de biomoléculas, mediante a introdução de elementos de afinidade. Por exemplo, na filtração por afinidade o ligante é anexado ao suporte que pode ser retido pela membrana de filtração. Em processo de dois estágios o meio a ser purificado é misturado com o adsorvente e os contaminantes não-ligados à matriz são removidos por filtração, enquanto o complexo enzima-ligante permanece no retentado. A enzima é logo eluida e recuperada do permeado mediante segundo processo de filtração. LUCAS et al. (1998) empregaram membranas de ultrafiltração modificadas com polietilemina para separar seletivamente a proteína $\alpha$-lactoalbumina a partir de concentrado protéico de soro de leite. Observaram separação seletiva de $\alpha$-lactoalbumina, que ficou retida na membrana.

\subsubsection{Precipitação por Afinidade}

A precipitação biosseletiva é possível mediante a utilização de ligantes específicos que induzem a precipitação das proteínas de interesse ou pela imobilização de ligantes em transportadores poliméricos, os quais podem ser precipitados. Essa técnica apresenta alta seletividade e vem sendo usada com muito sucesso na purificação de diversas enzimas e proteínas (79).

\subsubsection{Separação de Proteínas por Afinidade em Sistemas Aquosos Bifásicos}

Muitas proteínas apresentam interações únicas com pequenas moléculas, permitindo a alteração da partição e a obtenção de seletividade, cujo efeito é denominado de partição por afinidade. A extração seletiva com ligantes específicos imobilizados em um dos polímeros tem sido bastante efetiva (42). 
A partição por afinidade usando ligante específico pode ser limitada somente a uma das fases do SAB, anexado ao principal polímero dessa fase. Usualmente, apenas uma fração do polímero que forma essa fase é usada como transportador do ligante $(42,63)$.

SILVA et al. (1997) usaram o ligante específico APGP, acoplado ao PEG para purificar a enzima de Kleuveromyces lactis. Conseguiram recuperar $83 \%$ da enzima na fase superior do SAB composto por PEG-APGP/fosfato.

\section{NOVAS TÉCNICAS DE SEPARAÇÃO}

\subsection{LEITO MÓVEL SIMULADO (LMS)}

Uma série de colunas de adsorção (doze colunas, por exemplo), contendo adsorvente apropriado, são utilizadas no sistema de leito móvel simulado. As colunas são conectadas a recipientes que contêm a alimentação e 0 eluente, que recebem as correntes de saída do produto através de linhas controladas por um conjunto de válvulas de posições múltiplas. Esse conjunto de válvulas controladoras permite que sejam alternados, em intervalos de tempo regulares, os pontos de entrada da alimentação, do eluente e das correntes de saída. O sistema troca, portanto, as posições entre os pontos de entrada e saída, simulando o escoamento em contra corrente (77).

Em 1961 a United Oil Products (UOP) patenteou processo que permitia a simulação do movimento de um sólido por meio de conexão adequada entre as colunas (Figura 2). Esses sistemas cromatográficos contínuos têm sido utilizados em escala industrial, principalmente nas indústrias petroquímicas (Processos SORBEX e PAREX, desenvolvidos pela UOP) e de processamento de açúcares (52). Na atualidade, o sistema de leito móvel simulado é empregado com muito sucesso nos processos de separação nas indústrias de alimentos e de química fina (5).

O sistema de leito móvel simulado apresenta vantagens econômicas, por diversas razões, em relação aos outros sistemas cromatográficos em batelada. Trata-se de processo contínuo que permite a separação de mistura de compostos similares, possibilitando alta produção e baixo consumo de solvente. Em geral, nesse tipo de sistema, o volume de adsorvente necessário é aproximadamente $25 \%$ do requerido pela cromatografia em batelada (25). No caso de enzimas, o LMS foi utilizado por HUANG et al. (1986) para a purificação de tripsina a partir de extrato de pâncreas de 
porcos e por GOTTSCHLICH et al. (1996) para o estudo da purificação de quimotripsina bovina. GOTTSCHLICH e KASCHE (1997) também empregaram o LMS para a purificação de anticorpos monoclonais. Mais recentemente, AZEVEDO e RODRIGUES (2000) separaram frutose e glucose presentes em suco de caju, obtendo pureza ao redor de $90 \%$ de cada açúcar.

\section{FIGURA 2 - PRINCÍPIO DO LMS 12 DE COLUNAS}
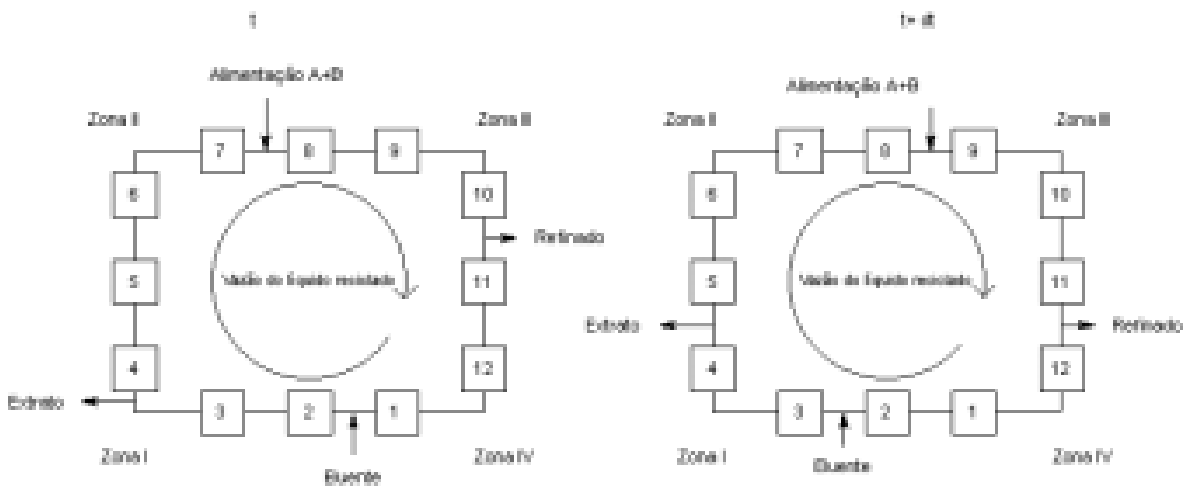

ronte: LUDEMANN-HUMBUURGER (2000).

\subsection{MICELAS REVERSAS}

A extração líquido-líquido usando micelas de fase reversa constitui nova técnica de separação que apresenta alta seletividade e facilidade no escalonamento, podendo ser operada continuamente $(39,40)$. A capacidade dos sistemas com micelas de fase reversa para extrair seletivamente a proteína-alvo duma mistura de compostos ainda não está completamente esclarecida. No entanto, sabe-se que pode ser influenciada por fatores como $\mathrm{pH}$, tipo e concentração do sal, tipo de solvente, temperatura e concentração do surfactante e incorporação do ligante (4). $\mathrm{Na}$ Tabela 7 são mostradas outras aplicações de extração com micelas de fase reversa.

\subsection{CROMATOGRAFIA EM CONTRACORRENTE}

A cromatografia em contracorrente originou-se dos estudos pioneiros de ITO et al. (1998), os quais construíram o primeiro equipamento no Japão. 
Esse foi projetado para separar partículas em suspensão ou solutos em solução com solvente, mediante campo de aceleração centrífuga. Pode ser definida como técnica cromatográfica que emprega duas fases líquidas imiscíveis, sendo uma dessas distribuída longitudinalmente em tubo vazio de maneira uniforme. A outra passa através dos tubos, sendo misturada com a primeira fase (73). Como ambas as fases são líquidas, os sistemas aquosos bifásicos compostos de dois polímeros ou de um polímero e um sal são usados, mais comumente, para separação de proteínas (20). Existem também outros sistemas de solventes usados na área de produtos naturais, ou seja, o sistema ternário composto por clorofórmio/metanol/ água e o quaternário composto por hexano/acetato de etila/metanol/água.

\section{TABELA 7- APLICAÇÕES DAS MICELAS REVERSAS NA EXTRAÇÃO DE BIOMOLÉCULAS}

\begin{tabular}{lc}
\hline Composto & Refercencia \\
\hline BSA & $(83)$ \\
$\alpha$-quimiotripsina & $(4)$ \\
Lisozima, ribonuclease e citocromo c & $(46)$ \\
$\alpha$-quimiotripsina & $(66)$ \\
Lisozima, ribonuclease e citocromo c & $(65)$ \\
Lisozima & $(40)$ \\
\hline
\end{tabular}

A técnica da cromatografia em contracorrente foi aplicada com muito sucesso na separação de diversas biomoléculas, devido a alta capacidade de recuperação e facilidade no manuseio das amostras. Por exemplo, OWEN e CHASE (1997) separaram lisozima mediante cromatografia em contracorrente utilizando equipamento contínuo de quatro estágios. Tais pesquisadores conseguiram purificação contínua, com $95 \%$ de rendimento e $66 \%$ de pureza.

\section{CONSIDERAÇÕES FINAIS}

Os avanços em biotecnologia representam potencial para a indústria de alimentos no desenvolvimento de novos produtos e processos. Esse desenvolvimento incluiria a purificação de biomoléculas, tais como enzimas e proteínas, a partir de meios complexos como os de fermentação ou de efluentes industriais. Assim, torna-se necessário o conhecimento das técnicas empregadas no processo de purificação de biomoléculas, sobretudo as técnicas cromatográficas. No entanto, deve-se considerar 
que ainda existem restrições técnicas e econômicas na aplicação de algumas dessas técnicas, principalmente em escala preparativa. Tais restrições não têm impedido que muitos laboratórios utilizem a cromatografia para a produção de substâncias com atividade biológica, de custo elevado no mercado, o que justificaria o emprego das técnicas cromatográficas na produção de alguns miligramas de substâncias com atividade biológica. Para que a purificação de biomoléculas de baixo valor comercial, em grande escala, possa ser economicamente viável novos desenvolvimentos na engenharia de processo e nas técnicas de separação devem ser realizados.

\section{Abstract}

REVIEW: TECHNIQUES UTILIZED IN BIOMOLECULES PURIFICATION PROCESS

The present literature review had as objective to show the different techniques that may be employed in biomolecules purification process. Besides selection and combination of separation techniques for the development of a purification strategy, precipitation, centrifugation, membrane technology (reverse osmose, ultrafiltration, dialysis and microfiltration), liquid-liquid extraction employing two phase aqueous systems, chromatography techniques (ion exchange, hidrophobic interactions, reverse phase, molecular exclusion, expanded bed), bio-selective separations (affinity chromatography, affinity precipitation, protein partition by affinity in two-phase aqueous system) and new separation techniques (simulated moving bed, reverse micelles, counter-current chromatography) was abborded. It was verified that chromatographic techniques are present in all biomolecules purification processes, although there are technical and economical restrictions in the application of some types of chromatography in preparative scale.

KEY-WORDS: BIOMOLECULES; CHROMATOGRAPHYC TECHNIQUES; PURIFICATION PROCESSES.

\section{REFERÊNCIAS}

1 ALBERTSSON, P.A. Partition of cell and macromolecules. New York: John Wiley, 1986. 346 p.

2 ALBERTSSON, P.A.; JOHANSSON, G.; TJERNELD, F. Aqueous two-phase separations. In: SEPARATION processes in biotechnology. New York: Marcel Dekker, 1990. p. 287-327.

3 ARAÚJO, M.O.D. Adsorção de albumina de soro bovino em resinas trocadoras de íons. Campinas, SP: FEQ, UNICAMP, 1996. 85 p. Dissertação (Mestrado), Faculdade de Engenharia Química, Universidade Estadual de Campinas.

4 ASHRAFIZADEH, S.; KHOSHKBARCHI, M. Modeling and experimental data for the reverse micellar extraction of proteins using new surfactant. Separation Science and Technology, v. 33, p.2579-2595, 1998. 
5 AZEVEDO, D.C.A.; RODRIGUES, A. Obtainment of high-fructose solutions from cashew (Anacardium occidentale) apple juice by simulated moving-bed chromatography. Separation Science and Technology, v. 35, p. 2561-2581, 2000 .

6 BENTLEY, P.; DICKINSON, F.M.; JONES, I.G. Purification and properties of rabbit muscle L-glicerol 3-phosphate dehydrogenase. Biochem. Journal, v. 135, p. 853-859, 1973.

$7 \quad$ BROCKLEBANK, M.P. Large scale separation and isolation of proteins. In: FOOD biotechnology. New York: Marcel Dekker, 1987 p. 139-192.

8 BROCKLEBANK, M.P. Downstream processing plant and equipment. In: SEPARATION processes in biotechnology. New York: Marcel Dekker, 1990. p. 617-740.

BRUCE, L.J.; GHOSE, S.; CHASE, H.A. The effect of column verticality on separation efficiency in expanded bed adsorption. Bioseparation, v.8, p. 69-75, 1999.

10 BUCKE, C. The biotechnology of enzyme isolation and purification. In: PRINCIPLES of biotechnology. New York: Gordon and Breach Science Publisher, 1983. p. 151171.

11 CHISTI, Y. Strategies in downstream processing. In: BIOSEPARATION and bioprocessing a handbook. New York: Marcel Dekker, 1998. v. 2, p. 3-30.

12 CLONIS, Y. D. Process affinity chromatography. In: SEPARATION processes in biotechnology. New York: Marcel Dekker, 1990. p. 401-445.

13 COIMBRA, J.S.R.; GIRALDO-ZUÑIGA, A.D.; LUIS A.M.; MEIRELLES A.J. Uso de sistemas aquosos bifásicos na extração líquido-líquido. Viçosa: UFV, 2002. (Série Caderno Didático, n. 95).

14 COIMBRA, J.R.; TÖMMES, J.; MEIRELLES, A.J.; KULA, M.R. Performance of graesser contactor in the continuous extraction of whey proteins: mixing, mass transfer and efficiency. Bioseparation, v. 5, p. 259-268, 1995.

15 COLLINS, C.H.; BRAGA, G.L.; BONATO, P.S. Introdução a métodos cromatográficos. Campinas: Unicamp, 1997. 279 p.

16 CUSSLER, E.L., DING, H. Bioseparation, especially using hollow fibers. In: BIOSEPARATION processes in foods. New York: Marcel Dekker, 1995. p. 1-55.

17 DORSEY, J.G., COOPER, W.T., SILES, A.A., FOLEY, J.P., BARTH, H.G. Liquid chromatography: theory and methodology. Anal. Chem., v. 70, p. 59-64, 1998.

18 ETZEL, M.R. Whey protein isolation and fractionation using ion exchangers. In: BIOSEPARATION processes in foods. New York: Marcel Dekker, 1995. p. 389415.

19 FANE, A.G.; RADOVICH, A.M. Membrane systems. In: SEPARATION processes in biotechnology. New York: Marcel Dekker, 1990. p. 209-262. 
20 FOUCAULT, A.P.; CHEVOLOT, L. Counter current chromatography: instrumentation solvent selection and some recent applications to natural product purification. Journal of Chromatography A, v.808, p.3-22, 1998.

21 GERBERDING, S.J.; BYERS, C.H. Preparative ion-exchange chromatography of proteins from dairy whey. Journal of Chromatography, v. 808, p.141-151, 1998.

22 GIRALDO-ZUÑIGA, A.D.; COIMBRA, J.S.R.; MINIM, L.A. Coeficientes de partição da $\alpha$-Lactoalbumina e $\beta$-Lactoglobulina em sistemas aquosos bifásicos :influência da massa molar do polímero. Cienc. Tecnol. Aliment., v. 3, n. 3, p. 149-155, 2001.

23 GLATZ, C.E. Precipitation. In: BIOSEPARATION and bioprocessing a handbook. New York: Marcel Dekker, 1998. v. 2, p. 329-356.

24 GOHEEN, S.C.; MATSON, R.S. Purification of human serum gamma globulins by hydrophobic interaction high performance liquid chromatography. Journal of Chromatography, v. 326, p. 235-241, 1985.

25 GOTTSCHLICH, N.; WEIDGEN, S.E.; KASCHE, V. Continuouos biospecific affinity purification of enzymes by simulated moving-bed chromatography: theoretical description and experimental results. Journal of Chromatography, v.719, p. 267-269,1996.

26 GOTTSCHLICH, N.E.; KASCHE, V. Purification of monoclonal antibodies by simulated moving-bed chromatography. Journal of Chromatography, v. 765, p.201-207, 1997.

27 GUPTA, M.N.;GUOQIANG, D.;MATTIASSON, B. Purification of endopolygalacturonase by affinity precipitation using alginate. Biotechnol. Appl. Biochem., v. 18, p. 321-324, 1993.

28 GUPTA, M.N.; GUOQIANG, D.; MATTIASSON, B. Purification of xylanase from Trichoderma viride by precipitation with an anionic polymer eudragist $\mathrm{S} 100$. Biotechnol. Tech., v. 8, p. 117-122, 1994.

29 HAHN, R.; SHULZ, P.M.; SCHAUPP, C.; JUNGBAUER, A. Bovine whey fractionation based on cation-exchange chromatography. Journal of Chromatography, v. 795, p.277-287, 1998.

30 HARRIS, E.L.; ANGAL, S. Protein purification methods: a practical approach. Oxford: Press Oxford, 1995. 317 p.

31 HEDDLESON, R.A.; ALLEN, J.C.; WANG, Q.W.; SWAISGOOD, H.E. Purity and yield of beta-lactoglobulin isolated by an $\mathrm{N}$-retinyl-Celite bioaffinity column. Journal of Agricultural and Food Chemistry, v. 45, n.7, p. 2369-2373, 1997.

32 HOLLAR, C.M.; LAW, A.J.R.; DALGLEISH, D.G.; ROWN, R.J. Separation and quantification of major casein fractions using cation-exchange fast protein liquid chromatography. Journal of Dairy Science, v. 74, p.2403, 1991. 
33 HUANG, S.Y.; LIN, C.K.; CHANG, W.H.; LEE, W.S. Enzyme purification and concentration by simulated moving bed chromatography: an experimental study. Chemical Engineering Communications, v. 45, p. 291-295, 1986.

34 HUSTED, H.; KRONER, K.H.; MENGE, U.; KULA, M.R. Partition in aqueous twophase systems. Trends Biotech, v.3, n.2, p.139-144, 1985.

35 HYDER, S.M.; WIEHLE, R.D.; BRANDT, D.W.; WITTLINF, J.L. High performance hydrophobic interaction chromatography of steroid hormone receptor. J. Cromatogra A, v.327, p. 237-246, 1985

36 IRVINE, G.B. Size-exclusion high-performance liquid chromatography of peptides: a review. Analytica Chimica Acta, v.352, p. 387-397, 1997.

37 ITO, Y.; MATSUDA, K.; MA, Y.; QI, L. Toroidal coil counter-current chromatography study of the mass transfer rate of proteins in aqueous-aqueous polymer phase system. Journal of Chromatography A, v. 802, p. 277-283, 1998.

38 JANSSEN, F.W.; RUELIUS, H.W. Alcohol oxidase, a flavoprotein from several basidiomycetes species: crystallization by fractional precipitation with polyethylene glycol. Biochim. Biophys. Acta, v. 151, p. 330-342, 1968.

39 JARUDILOKKUL, S.; POPPENBORG, L.H.; STUCKEY, D.C. Selective reverse micellar extraction of three proteins from filtered fermentation broth using response surface methodology. Separation Science and Technology, v. 35, p. 503-517, 2000.

40 JARUDILOKKUL, S.; PAULSEN, E.; STUCKEY, D.C (b). Lysozyme extraction from egg white using reverse micelles in a graesser contactor: mass transfer characterization. Biotechnology and Bioengineering, v. 69, n.6, p.618-626, 2000.

41 JOHANSSON, G.; ANDERSSON, M. Liquid-liquid extraction of glycolytic enzymes from baker's yeast using triazine dye ligands. Journal of Chromatography, v. 291, p. 175-183, 1984.

42 JOHANSSON, G. Affinity partitioning of proteins using aqueous two-phase systems. In: PROTEIN purification, principles, high resolution methods and application. New York: John Wiley, 1998. 695 p.

43 JOSIC, D.; SHUTT, W.; RENSWOUDE, J.V.; REUTER, W. High performance liquid chromatographic methods for antibodies, glycosidases and membrane proteins. Journal of Chromatography, v. 353, p. 13-18, 1986.

44 KATO, Y.; KITUMARA, T.; HASHIMOTO, T. Preparative high performance hydrophobic interaction of proteins on TSK gel phenyl-\%PW. Journal of Chromatography, v. 333, p. 202-210, 1985.

45 KATO, Y.; KITUMARA, T.; HASHIMOTO, T. New resin based hidrophobic support for high performance hydrophobic interaction chromatography. Journal of Chromatography A, v. 360, p. 260-265, 1986.

KULA, M.R.; KRONER, K.H.; HUSTED, H. Purification of enzymes by liquid-liquid 
extraction. Adv. Biochem. Engn, v. 24, p.73-118, 1982.

47 KUWATA, T.; PHAM, A.; NAKAI, S. Elimination of $\beta$-lactoglobulin from whey to simulated human milk protein. J. Food Science. v. 50, p 605-609, 1985.

48 LALI, A.; ARUNA, N.; JOHN, R.; THAKRAR, D. Reversible precipitation of proteins on carboxymethyl cellulose. Process Biochemistry, v. 35, p. 777-785, 2000.

49 LAUER, I.; BONNEWITZ, B.; MEUNIER, A.; BEVERINI, M. New approach for separating Bacillus subtilis metalloprotease and $\alpha$-amylase by affinity chromatography and for purifying neutral protease by hydrophobic chromatography. Journal of Chromatography B, v. 737, p. 277-284, 2000.

50 LI, M.; ZHU, Q.Z.; MEl. Partitioning of amino acids by aqueous two-phase systems combined with temperature-induced phase formation. Biotechnology Progress, v.13, n.1, p.105-108,1997.

51 LUCAS, D.; RABILLER-BAUDRY, M.; MILLESIME, L.; CHAUFER, B.; DANUFIN, G. Extraction of $\alpha$-lactalbumin from whey protein concentrate with modified inorganic membranes. Journal of Membrane Science, v. 148, p. 1-12, 1998.

52 LUDEMANN-HOMBOURGER, O.; NICOUD, R.M.; BAILLY, M. The "VARICOL" process: a new multicolumn continuous chromatographic process. Separation Science and Technology, v. 35, p.1829-1862, 2000.

53 MAA, Y.F.; HORVÁTH, C,S. Rapid analysis of proteins and peptides by reversedphase HPLC with polymeric micropellicular sorbents. Journal of Chromatography, v. 445, p. 71-86, 1988.

54 MANJI, B.; HILL, A.; KAKUDA, Y.; IRVINE, D.M. Rapid separation of milk proteins by anion exchange chromatography. Journal of Dairy Science, v.68, p. 3176-3179, 1985.

55 MATEJTSCHUK, P.; BAKER, R.M.; CHAPMAN, G.E. Purification and characterization of monoclonal antibodies. In: SUBRAMANIAM, G. Bioseparation and bioprocessing. New York: Wiley-VCH Verlag, 1998. v.2, p. 234-253.

56 MIDDELBERG, A.P.J.; O'NEILL, B.K. Harvesting recombinant protein inclusion bodies. In: SUBRAMANIAM, G. Bioseparation and bioprocessing. New York: WileyVCH Verlag, 1998. v.2, p. 81-129.

57 MILLER, N,T.; FEIBUSH, B.; KARGER, B.L. Wide-pore silica-based ether bonded phases for separation of proteins by high performance hydrophobic interactions and size exclusion chromatography. Journal of Chromatography, v. 316, p. 519-536, 1985.

58 MORR, C.; HA, E.W. Whey protein concentrates and isolates processing and functional properties critical reviews. Food Science and Nutrition, v.33, n.6, p.431-476, 1993.

NIVEN, G.W. Separation processes for biotechnology in the food industry. In: 
FOOD processing: recent developments. New York: Elsevier Science, 1995. p. 143-195.

60 OWEN, R.; CHASE. H.A. Direct purification of lysozyme using continuous expanded bed adsorption. Journal of Chromatography A, v. 757, p. 41-49, 1997. B

61 PASECHNIK, V.A.; PHLS, J.M. Large-scale extraction and purification of enzymes and other proteins. In: HANDBOOK of enzyme biotechnology. New York: Wiseman, 1995. p.31-82.

62 PEREIRA, J.A.M. Adsorção de beta-galactosidase de Scopulariopsis sp. em resina trocadora de íons objetivando a purificação e a ampliação de escala, Campinas, SP: FEQ, UNICAMP, 1999. 138 p. Dissertação (Doutorado), Faculdade de Engenharia Química, Universidade Estadual de Campinas.

63 PERSSON, L.O.; OLDE, B. Synthesis of atp-polyethylene glycol and Atp-dextran and their use in the purification of phosphoglycerate kinase from spinach chloroplast using affinity partitioning. Journal of Chromatography, v. 457, p. 183-193, 1988.

64 PHARMACIA BIOTECH. Protein purification handbook. Sweden, 1999. $97 \mathrm{p}$.

65 POPPENBORG, L.H.; BRILLIS, A.A.; STUCKEY, D.C. The kinetic separation of protein mixtures using reverse micelles. Separation Science and Technology, v. 35, p.843-858, 2000.

66 RABIE, H.R.; VIERA, J.H. A simple model for reverse micellar extraction of proteins. Separation Science and Technology, v. 33, p.1181-1193, 1998.

67 RASSI, E.A.Z.; LEE, A.L.; HORVÁTH, C. Reversed-phase and hydrophobic interaction chromatography of peptides and proteins. In: SEPARATION processes in biotechnology. New York: Marcel Dekker, 1990. p.447-494.

68 RICKER, R.D.; SANDOVAL, A.A. Fast, reproducible size-exclusion chromatography of biological macromolecules. Journal of Chromatography, v. 743, p.43-50, 1996.

69 RITO-PALOMARES, M.; HUDDLESTON, J.G.; LYDDIATA, A. PEG-phosphate aqueous two-phase partitioning polymer recycling in practical implementation. Trans I. Chem., v. 72, p. 11-13, 1994.

70 ROSENBERG, M. Current and future applications for membrane processes in the dairy industry. Trends in Food Science \& Technology, v. 6, p. 12-16, 1995.

71 SAKSENA, A.; ZYDNEY, A.L. Effect of solution $\mathrm{pH}$ and ionic strength on the separation of albumin from immunoglobulins by selective filtration. Biotechnology and Bioengineering, v. 43, p 960, 1994.

72 SARDAR, M.; GRUPTA, M.N. Alginate beans as an affinity material for $\alpha$-amylases. Bioseparation, v. 7, p. 159-165, 1998. 
73 SHIBUSAWA. Y.; KIHIRA S.; ITO, Y. One-step purification of proteins from chicken egg white using counter current Chromatography. Journal of Chromatography B, v. 709, p. 301-305, 1998.

74 SILVA, M.A.E.; PELLOGIA, C.; PIZA, F.A.T.; FRANCO, T.T. Purification of three different microbial $\beta$-galctosidase by partitioning in aqueous two phase systems. Ciênc. Tecnol. Alimen., v. 17, n. 3, p. 219-223, 1997.

75 SINGH, R.P.; HELDMAN, D.R. Introduction to food engineering. $2^{\text {nd }}$ ed. San Diego, USA: Academic Press. 1993. 499p.

76 STERNBERG, M.; HERSHBERGER, D. Separation of protein with polyacrylic acids. Biochim. Biophys. Acta, v. 342, p. 195-206, 1974.

77 STRUBE, J.; ALTENHONER, U.; MEURER, M.; SCHMIDT-TRAUB, H.; SCHULTE, M. Dynamic simulation of simulated moving bed chromatographic processes for the optimization of chiral separations. Journal of Chromatography, v. 769, p. 8192, 1997.

78 SUBRAMANIAM, Ganapathy. Bioseparation and bioprocessing. New York: Wiley-VCH Verlag, 1998. v.2, 474 p.

79 TEOTIA, S.; KHARE, S.K.; GUPTA, M.N. An efficient purification process for sweet potato beta-amylase by affinity precipitation with alginate. Enzyme and Microbial Technology, v. 28, p. 792-795, 2001.

80 TWEETEN, K.A.; TWEETEN, T.N. Reversed-phase chromatography of proteins on resin-based wide-pore packings. Journal of Chromatography, v. 359, p. 111119, 1986.

81 WANG, Q.W.; SWAISGOOD, H.E. Characteristics of beta-lactoglobulin binding to the all -trans-retinal moiety covalent immobilized on celite $(\mathrm{Tm})$. Journal of Dairy Science, v. 76, n.7, p.1895-1901, 1993.

82 WESTFALIA, Oelde. Germany. Disponível em: <http://www.gea-westfalia.be>. Acesso em $1 \mathrm{dez} .2001$

83 ZHANG, T.; LIU, H.; CHEN, J. Affinity-based reversed micellas bovine serum albumin (BSA) extraction with unbound recative Dye. Separation Science and Technology, v. 35, p.143-151, 2000. 